\title{
A NEW SPECIES OF SPIKE-RUSH FOR SASKATCHEWAN
}

\author{
by John H. Hudson, Saskatoon
}

This summer I had little chance to do much botanical travelling in search of unusual habitats and rare species, having upon hand a new yard which needed fencing and landscaping. My botanizing was restricted to afternoon trips of a few miles from Saskatoon, and became intensive rather than extensive. As the season advanced I found that slough bottoms in tilled fields carry a flora of common but little known or collected species (about which more in a later article). Among these I had the good luck to find a plant not reported for Saskatchewan in most manuals, Eleocharis engelmannii Steud.

A general description of the genus Eleocharis or Spike-rush may be of interest to outdoor folk. Many have doubtless seen the two common species without paying them any attention, or distinguishing them from the multitude of habitally similar bulrushes (Scirpus) and rushes (Juncus) which crowd about wet or lately wet places.

The above-ground structure of spike-rushes could hardly be simpler. One sees one or more green unjointed stems, leafless and usually tubular, tipped by a brown inflorescence not much broader than the stem. The cigar-shaped terminal inflorescencestrictly speaking, a spike--is made up of small brown scales spirally arranged on the stem. Behind each scale is a well-hidden flower, bisexual, with two or three stamens and a pistil. The pistil ripens into a bare achene (essentially, a seed). This achene is adorned with a more or less triangular tubercle or wart, representing the hardened base of the style. As separation of the species in the genus is done largely on details of the shape, colour, and texture of the achene and its tubercle, and as this tubercle is at most $1.5 \mathrm{~mm}$. long and so needs at least a $10 \mathrm{X}$ lens for its study, one may see why the genus is little observed by naturalists.
Breitung (1957) reported four species of Eleocharis in Saskatchewan, of which two (E. palustris and $E$. acicularis) are common, the other two rare. (There is some E. acicularis, about an inch high, showing in Fig. 1). He listed the subject of this article, $E$. engelmannii, as an excluded species - one which had been reported for the province in a current manual, but for which he could find no evidence in field or herbarium. Of what lies behind this I am ignorant.

Eleocharis engelmannii is, however, not hard to recognize after having been met once. Its most conspicuous feature is its densely bunched habit. Some 20-50 or more of the simple stems radiate in every direction from one point (the crown) at ground level. The photos show this well. It is an annual, thus the crown is soft and no creeping rootstocks can be found. Another recognition point is the white, papery, sleevelike sheaths, representing rudiments of leaves, of which several may be seen at each stem base of the living plant. I shall not go into achene characters, as their study calls for high magnification and the plant can be recognized without them.

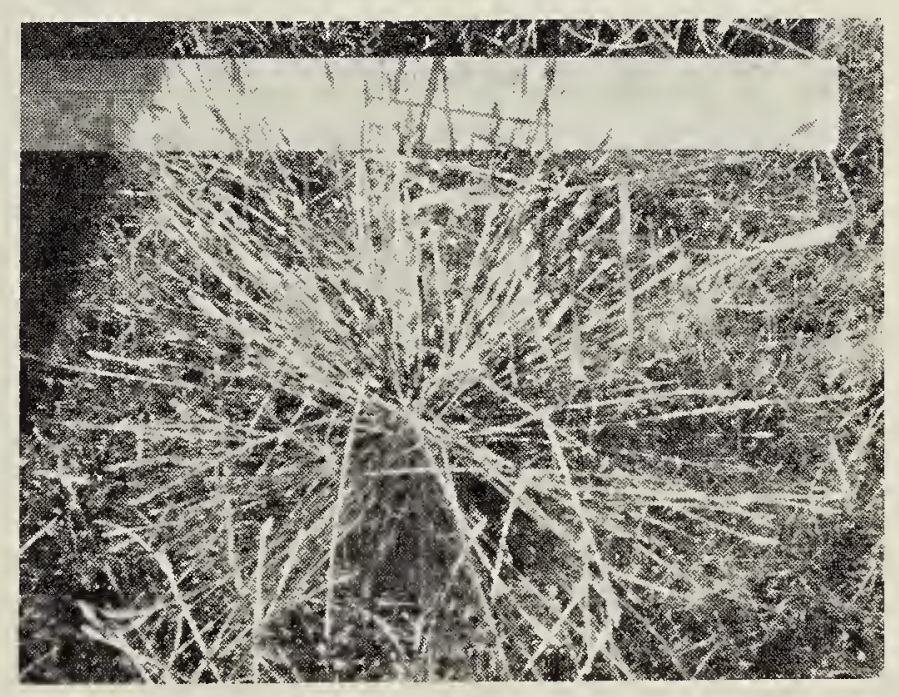

Figure 1. Eleocharis engelmannii in place, from above. Ruler in inches. The background vegetation, like rug piling, is Eleocharis acicularis. 


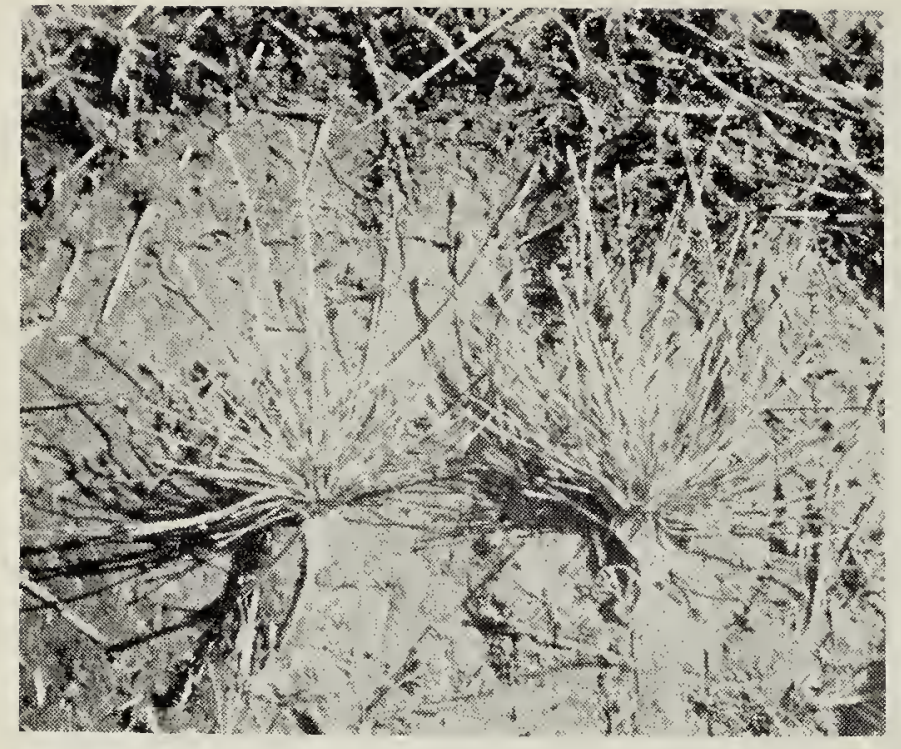

Figure 2. Eleocharis engelmannii. Side view of pulled-up plants.

The habitat appears to be dry slough bottoms in farmed fields; I have not seen the plant on undisturbed sites. As to its distribution in Saskatchewan, nothing is known except that it occurs in quite a few field slough bottoms near Saskatoon. Beyond our borders there are reports of this or closely allied forms from Manitoba by Scoggan (1957), from Alberta by Moss (1959), and from North Dakota by Stevens (1950). Standard eastern manuals ascribe the plant a wide distribution in the eastern States and adjacent Canada, as well as on the Pacific coast. The latest of these manuals, Gleason and Cronquist (1962), merges $E$. engelmannii into $E$. ovata (L) R. \& S., a plant of like range in the East but not at all reported in the West.

Collections are: J. H. Hudson \#2247, 7 August 1965, W. edge N.W.1 5-37-VI w3rd ( $7 \mathrm{mi} \mathrm{N.W.} \mathrm{of} \mathrm{Saska-}$ toon), dry field pot-hole on clayey soil; J. H. Hudson \#2253, 11 August 1965, S.W. cor. S.E. $\frac{1}{4} 1-37-V$ w3rd (just E. of Sutherland, 3 miles by road from the University), field pot-hole, soil clayey and not too long ago muddy. Also seen on 21 August on N.E. cor. S.E. $\frac{1}{4}$ 19-37-V w3rd (5 mi. N. of Saskatoon), and on 8 September on N. edge N.W. $\frac{1}{4}$ 21-36-IV w3rd (5 mi. E. of Saskatoon). The pictures were taken at this last place. These collections and sightings fill in a gap in the distribution of the species, even if its precise name be a little uncertain.

Duplicates of the collections will be sent to the W. P. Fraser Herbarium at the University and to that of the Department of Agriculture at Ottawa.

\section{LITERATURE CITED}

Breitung, A. J. 1957. Annotated catalogue of the vascular flora of Saskatchewan. American Midland Naturalist, 58 (1), pp. 1-72.

Gleason, H. E., and A. C. Cronquist. 1962. Manual of vascular plants of N.E. United States and adjacent Canada. New York, D. Van Nostrand.

Moss, E. H. 1959. Flora of Alberta. University of Toronto Press.

Scoggan, H. J. 1957. Flora of Manitoba. National Museum of Canada Bulletin, No. 140 .

Stevens, O. A. 1950. Handbook of North Dakota Plants. Fargo, North Dakota Institute for Regional Studies.

\section{W. C. MCCALLA PHOTOGRAPH SERIES}

The photograph on the opposite page ends a series of splendid studies of plants given to the Blue Jay by the late Dr. W. C. McCalla, and published for some years as a regular feature. When Dr. McCalla died in 1962, Dr. George Ledingham, then Editor, still had some of his photographs and these have continued to appear in the Blue Jay as a fitting memorial. As this last picture in the series is printed, it seems appropriate to quote Dr. McCalla's own words on his hobby, as he turned over his albums to the National Museum of Canada: "These photographs were taken over a long period of time and under all kinds of conditions; there were frequent difficulties, I often breathed something like a prayer that I might be able to do justice to the beauty of Nature in front of the camera. I had no thought of the financial value of what I was doing. The work was fascinating, challenging, sometimes disappointing, often rewarding - a grand avocation adding to the interest and joy of life." 